\title{
Proximate causes and fitness consequences of hatching failure in lesser kestrels Falco naumanni
}

\author{
David Serrano, Jose' L. Tella and Esperanza Ursu'a
}

\begin{abstract}
Serrano, D., Tella, J. L. and Ursu'a, E. 2005. Proximate causes and fitness consequences of hatching failure in lesser kestrels Falco naumanni. -J. Avian Biol. 36: 242 -250.

Hatching failure is a pervasive phenomenon in birds, but factors affecting hatchability remain poorly understood. We studied proximate causes and fitness consequences of hatching failure in a long-monitored population of the colonial lesser kestrel Falco naumanni . We investigated whether hatchability was related to clutch characteristics, parental traits, and social or environmental features. Hatching failure represents a cost for the parents in terms of immediate fitness, since it reduced both their number of young fledged and recruits in the breeding population, even when controlling for clutch size. Hatching failure showed a non-linear relationship with clutch size, clutches of four eggs showing higher levels of hatching success than larger or smaller clutches. Hatchability could therefore play a role in the evolution of optimal clutch size in this species, at least constraining the maximum number of eggs the parents can afford to incubate. Contrary to most studies, the mean volume of the clutch and the individual egg volume were negatively related to hatching failure, indicating that large eggs have thermoregulatory and/or nutritional advantages. Mean daily maximum temperature during incubation affected hatching success negatively, but only for females in poor condition. This result seems to indicate that females are reluctant to jeopardize their own condition, but instead sacrifice incubation effort by paying the costs of a lower hatching success in circumstances of high temperatures. There was no evidence that hatching failure was related to the intrinsic properties of individuals or genetic similarity between the parents as indicated by low repeatabilities of: (1) males that bred with different females, (2) females that bred with different males, and (3) pairs breeding together in different years. Neither colony size nor subpopulation size affected hatchability. All these findings show how hatching failure is simultaneously influenced by several factors acting in a complex way, which could in part explain the apparently conflicting conclusions of empirical or even experimental studies carried out to date.
\end{abstract}

D. Serrano (correspondence ), J. L . Tella and E. Ursu'a . Department of Applied Biology. Estación Biolo'gica de Doñana (C.S.I.C.) Pabellón del Peru’Avda Marı́a Luisa s/n 41013 Sevilla Spain.E-mail : serrano @ebd .csic .es

Hatching failure is a widespread phenomenon in birds that has potential fitness costs for individuals. About $10 \%$ of the eggs produced fail to hatch (Koenig 1982), in spite of presumably strong natural selection to maximize fertility. However, factors constraining hatchability have received remarkably little attention compared to other breeding parameters. Eggs fail to hatch due to embryo death or lack of fertilization (Rothstein 1973), and an array of factors have been proposed to explain both phenomena (see Morrow et al. 2002 for a review).
It has been suggested that genetic similarity between the parents, i.e. inbreeding, affects negatively egg hatchability (Bensch et al. 1994, Kempenaers et al. 1996). This and other genetic causes may result in hatching failure due to, for example, the homozygous expression of recessive lethal alleles (Charlesworth and Charlesworth 1987), incompatibility between male and female gametes (Zeh and Zeh 1996), or poor fertilization ability of the sperm (Gemmell and Allendorf 2001). 
On the other hand, eggs require particular conditions of temperature and humidity rarely provided by natural environments, so parents must regulate nest microclimate by incubation (Webb 1987). Thus, they must face the conflicting demands of two mutually exclusive activities: parental care and self-maintenance. Given that energy expenditure increases with incubation effort (Moreno et al. 1991, Thompson et al. 1998), parental care during incubation is expected to be state-dependent. In this way, birds in poor condition may provide less parental care (Smith et al. 1989, Mallory and Weatherhead 1993, Spencer and Bryant 2001), which could increase the proportion of unhatched eggs. Consistently, experimentally fed birds, or birds fed with a diet rich in proteins have been shown to have higher hatching success than unfed pairs or pairs fed with a poorer nutritional diet (Gill et al. 2002, Gorman and Nager 2003). Apart from the state of individuals, hatchability may be affected by other individual traits. For example, hatchability has been reported to be age-dependent (Newton and Rothery 2002, Milonoff et al. 2002), sizedependent (Bortolotti and Wiebe 1993), and to vary with the breeding phenology (Hendricks and Norment 1994). However, there are species in which these relationships have not been detected (see e.g. Potti and Merino 1996). Other factors affecting hatchability are clutch size (Potti and Merino 1996) and egg volume (Wiebe and Bortolotti 1995, Potti and Merino 1996). Again, contradictory results have been found (e.g. Hendricks and Norment 1994, Clifford and Anderson 2002), even in experimental studies of clutch size manipulation within the same species (see Moreno and Carlson 1989, Siikama"ki 1995, Ilmonen et al. 2002 for the pied flycatcher Ficedula hypoleuca , and Moreno et al. 1991, Cicho'n 2000 for the collared flycatcher Ficedula albicollis ). Some of these discrepancies may result from complex interactions among several factors, so more research is clearly needed. small-bodied species that are unable to rely on endogenous reserves for a long time. Weather-mediated behavioural responses may therefore obscure factors affecting hatchability due to, for example, favourable ambient temperature or food supply during incubation (Wiebe and Martin 2000).

In this study, we investigated the proximal causes and fitness consequences of hatching failure in a long-term monitored, individually-marked population of the colonial lesser kestrel Falco naumanni . This population has increased dramatically during the study period (Serrano et al. 2003), and is divided in a variable number of discrete subpopulations spatially isolated and with different sizes (Serrano and Tella 2003). Our objectives were: (1) to investigate if hatching failure represents a cost for the parents or if, alternatively, they compensate egg-failure by lower mortality rates of the chicks in the nest and/or higher rates of offspring recruitment into the breeding population, (2) to test whether hatching failure was related to clutch characteristics such as clutch size and egg volume, (3) given that nest attentiveness is expected to be state-dependent, to investigate the role played by several individual and phenotypic traits on hatchability, (4) to study if hatching failure is related to intrinsic properties of individuals, for example to functional infertility, by investigating how consistent is hatching failure within individuals, and (5) to investigate if levels of genetic similarity affect hatching success in lesser kestrels. A prediction of this hypothesis is that hatching failure of pairs breeding together should be highly repeatable between years. Other objectives were:

(6) to study if hatching failure varies with colony size, and thus is a fitness component potentially influencing the relationship between costs and benefits of coloniality, (7) to explore spatio-temporal variations in hatching failure, and (8) to investigate if hatching failure is affected by weather conditions during incubation.

\section{Methods Study area and}

\section{species}

The study was conducted between 1993 and 2002 in the population of lesser kestrels of the Ebro Valley, northeastern Spain. There, lesser kestrels breed solitarily or in colonies of 2-50 pairs under tiled roofs of abandoned farmhouses surrounded by traditionally farmed cereal crops (Tella et al. 1998). Lesser kestrels are insectivorous, long-distance migrants arriving to the breeding colonies in February and leaving for their wintering grounds in September. They lay $2-6$ eggs, usually 4-5, that are incubated for 28 days. Both sexes have a well developed brood patch and are incubated at daylight, but only females incubate at night. 


\section{Field procedures}

Nests were located well before laying by watching pairs of kestrels from hides with telescopes. At this time, we noted each pair and each nest in detailed schemes of the roofs. From mid-April, a number of focal nests was monitored each year to record clutch size. Each egg was marked with a water proof felt-tip pen. Posterior visits to focal nests allowed us to record the fate of each egg and to band the chicks in colonies where nest-switching may confound breeding success (Tella et al. 1997). From early July, we visited as many nests as possible in the whole population to band the rest of the fledglings and to obtain the breeding success of each pair. Fledglings and adults captured in the nests were banded with a metal band, and a plastic colour band engraved with a unique alpha-numeric code to be read at distance. As many birds were banded each year, we know the exact ages of most parents (Serrano et al. 2001, 2003, 2004 for more details about field procedures).

We defined as unhatched eggs those that survive the entire incubation period but failed to hatch. Therefore, we excluded from the data set those clutches that were depredated or abandoned during the incubation period, because the action of predators or the death of the parents may confound intrinsic hatchability. We also excluded nests with eggs found broken accidentally. Only those nests visited shortly after hatching were considered, so we are confident that our estimates of hatching failure were reliable.

It has been largely assumed that unhatched eggs having no visible embryo are infertile (Wetton and Parkin 1991), but it is hard to distinguish infertile eggs from those whose embryo died in the earliest stages of development (Birkhead et al. 1995). We did not try to distinguish between both types of causes when analyzing hatching failure, and we used the terms unhatched and non-viable eggs along the paper to designate any egg that failed to hatch.

For each nest, the following data was recorded: (1) clutch size, and (2) laying date, estimated by the length of the eight primary of the largest chick within each brood (Negro et al. 1997). This variable was also standardized with respect to annual mean to control for variations among years, but results did not change substantially, (3) Age of the mother in years. (4) age of the father, as above, (5) size of the mother estimated by its wing length (to the nearest $0.5 \mathrm{~mm}$ and measured by the maximum method), as a reliable measure of body size in this species (Tella 1996). (6) Size of the father, as above. (7) Colony size, i.e. number of breeding pairs. (8) Body condition of the parents during incubation. This variable was calculated using the residuals of a linear regression of log body mass (on log wing length). In the case of females, log days after laying the first egg was also included as a covariate to control for loss of female body mass along the incubation (Dona'zar et al. 1992).
We also measured maximum length and breath of each egg (to the nearest $0.1 \mathrm{~mm}$ ) in 208 clutches in 1993, 1994, and 1995. Egg volume was estimated following Hoyt (1979).

Daily weather information was recorded at the meteorological stations of Zaragoza airport, Candasnos, Quinto, Hijar, and Fraga. For each colony, we used the data of the nearest station, which was in all the cases at a distance of less than $30 \mathrm{~km}$. Data included daily minimum and maximum temperatures, daily precipitation, and daily wind speed. Weather data for each clutch was calculated as the mean value during the 32 days after onset of laying.

\section{Data analysis}

Causes and consequences of hatching failure were analysed using Generalized Linear Modelling techniques. As hatching failure was usually monitored in the same colonies within and among years, we modelled variance-covariance structures with Generalized Linear Mixed Models (GLMMs, see Littell et al. 1996), which allow us to control for potential non-independence in the data set. When analyzing causes of hatching failure, fixed explanatory variables and their interactions were fitted to the observed data following both a forward and a backward variable-selection procedure, and we obtained the same model results. Quadratic and cubic effects were also incorporated into the models to account for potential nonlinear relationships.

Fitness consequences of hatching failure were investigated by analysing the effect of hatching failure on both the number of fledglings and the number of young recruited in the breeding population per nest. In these analyses, we included clutch size as a covariate, year as a fixed factor, and colony as a random factor. As detailed reading of plastic bands lasted until year 2000, and most individuals recruited in the breeding population when one or two years-old (Serrano et al. 2003), we only analysed those cohorts for which at least two years had elapsed fledgling, i.e. 1993 -1998. Since emigration rates from our studied population, if existing, were negligible (see Serrano et al. 2001, 2003), we are confident that fledglings returning to breed reflected accurately offspring recruitment rates.

To investigate causes of hatching failure, we carried out several analyses. First, we conducted a GLMM with all independent variables, except egg volume, as fixed effects, and colony identity as a random term. Given that the causes of hatching failure could be obscured by clutch size, we used a dependent variable in which the number of unhatched eggs was the numerator and the whole number of eggs in each clutch was the binomial denominator, to not lose information on clutch size (Crawley 1993). As we only measured eggs in 1993, 1994 
and 1995, the potential effect of egg volume on hatchability was analysed separately by building a similar GLMM in which mean egg volume in the clutch was incorporated as a predictor fixed variable. In a third GLMM, we analyzed the effect of individual-egg volume on its probability of non-hatching. For this analysis, we used a binomial dependent variable ( $0=$ hatched, $1=$ unhatched), and controlled for non-independence of observations by including colony identity and nest identity nested in colony identity as random terms. Appropriate link functions and error structures for Poisson and binomially distributed data were implemented by using the SAS macro GLIMMIX. Hypotheses were tested using F-statistics. In simple situations, denominator degrees of freedom are calculated as the number of observations or observation proportions minus the number of independent effects parameters, but in more complex cases GLIMMIX uses a Satterthwaite-type procedure (Littell et al. 1996). Given that we have missing values of some variables, sample sizes varied somewhat among analyses.

Finally, we calculated repeatabilities of the proportion of non-viable eggs using the intraclass correlation coefficient (Lessells and Boag 1987). If hatching failure results from functional infertility or other factors determining long-term individual quality, the proportion of unhatched eggs of the same individual should be repeatable among years. If hatchability is related to genetic similarity between the parents, we expected the proportion of non-viable eggs of the same pair to be repeatable in different years. Therefore, we calculated repeatabilities for: (1) males that bred with different females, (2) females that bred with different males, and

(3) pairs that bred together in different years. All tests were two-tailed.
4.7-10.6\% (Table 1), although there were not significant differences among years $(\mathrm{F} 9,818=0.91, \mathrm{P}=0.52)$, nor among subpopulations $\left(\mathrm{F}_{10}, 828=0.89, \mathrm{P}=0.55\right)$. Most nests with hatching failure had only one unhatched egg (69.9\%), 23.6\% had two, $5.3 \%$ three, and only $1.2 \%$ four.

Number of young fledged per nest in absence of predation was negatively related to the number of non-viable eggs after controlling for clutch size (Table 2, Fig. 1A). Moreover, although recruitment rates into the breeding population varied among cohorts, the number of offspring recruited per nest was also negatively affected by the number of non-viable eggs after controlling for clutch size (Table 2, Fig. 1B). Parents are therefore unable to fully compensate non-viable eggs, so hatching failure seems to represent an important cost for them.

With respect to causes of hatching failure, our multivariable analysis showed a quadratic effect of clutch size on the proportion of unhatched eggs (Table 3). Thus, the lowest rates of hatching failure occurred in clutches of four eggs, while clutches of smaller or greater size had a higher percentage of unhatched eggs (Fig. 2). When laying date was included into the model, there was a positive relationship with hatching failure, birds laying relatively late in the season having the highest percentage of unhatched eggs $(0.18890 .070$ (estimate91 SE), F1, 793=7.20; $\mathrm{P}=0.007)$. However, this effect disappeared when female body condition, mean daily maximum temperature, and their interaction was taken into account in the model (Table 3). This interaction indicated that hatching failure increases with mean daily maximum temperatures during incubation for females in poor body condition, but not for females in good condition (Fig. 3). Hatchability was not related to other individual traits such as age or size of the parents (all $\mathrm{P}$-values $>0.20$ ), nor to the number of breeding pairs at a colony $(\mathrm{P}=0.68)$. Multivariable analysis neither showed significant variation of hatching failure among years $(\mathrm{P}=0.45)$, or subpopulations $(\mathrm{P}=0.66)$.

\section{Results}

Excluding all cases of predation, nest desertion and accidental breakage, $8.20 \%$ of the eggs failed to hatch $(n=4136)$, affecting $25.5 \%$ of the nests $(n=963)$. The proportion of unhatched eggs varied annually between

Hatching failure was negatively related to mean egg volume in the clutch $(-0.45490 .160, \quad F 1,104=8.09, \quad \mathrm{P}=0.005)$. This relationship persisted after controlling for clutch size and mean daily maximum temperature $\left(-0.44790 .195, F_{1}, 99=5.27\right.$, $\mathrm{P}=0.024)$.

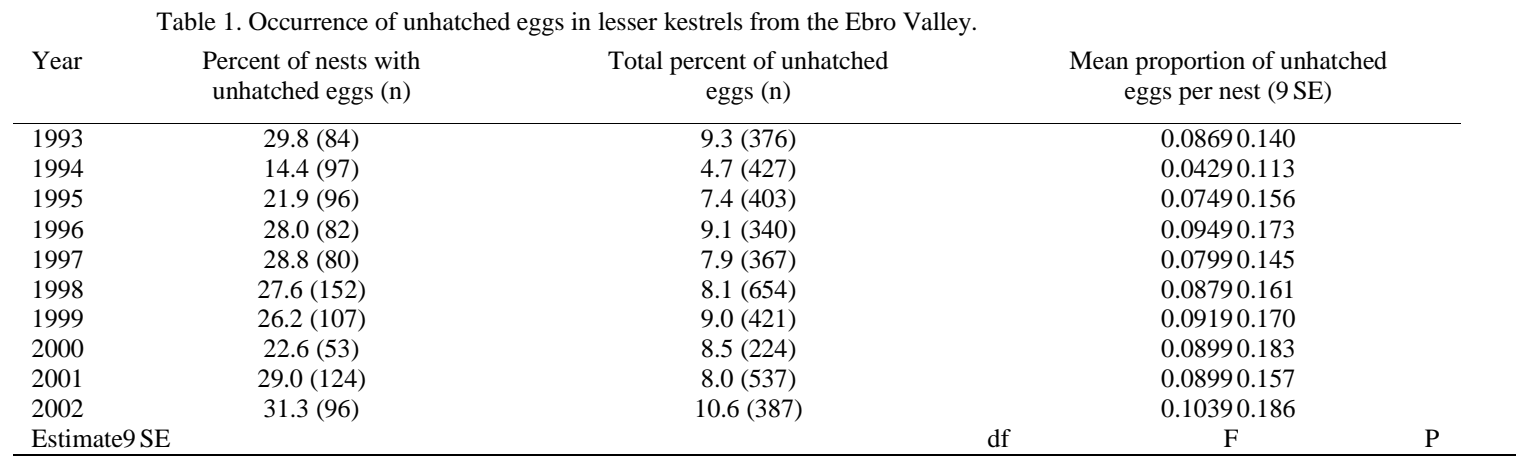


Table 2. Results of the mixed models explaining number of young fledged and number of young recruited per nest. A Poisson error with a log link function was used in both models. Clutch size, number of unhatched eggs, and year were included as explanatory variables. Colony site was included as a random factor. Year and all interactions were not retained into the model of young fledged (all P-values $>0.15$ ). No interactions were retained into the model of young recruited. (all P-values $>0.19$ ).

\begin{tabular}{lccc} 
Year & $\begin{array}{c}\text { Percent of nests with } \\
\text { unhatched eggs (n) }\end{array}$ & $\begin{array}{c}\text { Total percent of unhatched } \\
\text { eggs (n) }\end{array}$ & $\begin{array}{c}\text { Mean proportion of unhatched } \\
\text { eggs per nest (9SE) }\end{array}$ \\
\hline 1993 & $29.8(84)$ & $9.3(376)$ & 0.08690 .140 \\
1994 & $14.4(97)$ & $4.7(427)$ & 0.04290 .113 \\
1995 & $21.9(96)$ & $7.4(403)$ & 0.07490 .156 \\
1996 & $28.0(82)$ & $9.1(340)$ & 0.09490 .173 \\
1997 & $28.8(80)$ & $7.9(367)$ & 0.07990 .145 \\
1998 & $27.6(152)$ & $8.1(654)$ & 0.08790 .161 \\
1999 & $26.2(107)$ & $9.0(421)$ & 0.09190 .170 \\
2000 & $22.6(53)$ & $8.5(224)$ & 0.08990 .183 \\
2001 & $29.0(124)$ & $8.0(537)$ & 0.08990 .157 \\
2002 & $31.3(96)$ & $10.6(387)$ & 0.10390 .186 \\
Estimate9SE & & & $\mathrm{F}$ \\
\hline
\end{tabular}

Young fledged

Moreover, individual-egg analysis showed a significant negative relationship between probability of non-hatching and egg volume (-0.2559 0.129, $\mathrm{F}_{1}, 446=3.87, \mathrm{P}=0.05$; see Fig. 4).

Finally, the proportion of unhatched eggs was not repeatable for individual males $\left(\mathrm{r}=0.09, \mathrm{~F}_{87}, 117=1.22, \mathrm{P}=0.16\right)$, individual females $\left(\mathrm{r}=0.02, \mathrm{~F}_{130}, 170=0.94, \mathrm{P}=0.64\right)$, or pairs $(\mathrm{r}=0.12, \mathrm{~F} 13,15$ $=0.77, \mathrm{P}=0.67)$.

\section{Discussion}

Hatching failure in lesser kestrels affected around $8 \%$ of the eggs, which was similar to that reported for other bird species (Koenig 1982). However, non-viable eggs were less common in our population than in other Spanish populations of lesser kestrels: Aparicio (1997) reported 17\% of unhatched eggs in La Mancha, Bijlsma et al. (1990) 19\% in Extremadura, and Negro et al. (1993) 20\% in Andalucia, although the later two authors included in their estimates nests deserted before hatching. Our measures of hatching failure are unlikely to be under-estimated, as hatchability was estimated from hundreds of nests visited during incubation, and a few days after hatching. It is possible that specific ecological or environmental characteristics of each population, or even research disturbance during repeated monitoring of clutches, explained these variations in hatchability among studies.

Whatever the causes of these differences, the presence of unhatched eggs reduced breeding performance in lesser kestrels even taking into account initial clutch size. Therefore, parents seem unable to fully compensate eggfailure with extra parental care and thus with higher rates of offspring survival from hatching to fledgling with respect to clutches with all eggs hatching successfully. There is also the possibility of the classical tradeoff between offspring number and quality, chicks of larger broods leaving the nest with poorer body condition (see Tella et al. 2000 for American kestrels), which could affect their future survival and recruitment. However, offspring recruitment was also negatively affected by the number of non-viable eggs, also controlling for clutch size. Therefore, hatching failure seems to be an important cost in this species that could seriously affect individual fitness.

Our analysis of the factors causing hatching failure showed a quadratic effect of clutch size on hatchability. In this way, hatching success was higher in clutches of four eggs than in smaller or larger clutches. To our knowledge, only Hunt and Hunt (1973) found a similar pattern of highest hatchability in intermediate clutches of western gulls Larus occidentalis. Several studies have demonstrated experimentally that clutch size enlargement is associated with higher energy expenditure in incubating females (Moreno et al. 1991, Tatner and Bryant 1993, Moreno and Sanz 1994). Incubating extra eggs may therefore affect negatively female condition (Jones 1987, Moreno and Carlson 1989), and/or nest attendance during incubation (Wiebe and Martin 2000). Thus, poor incubation performance and inability to maintain optimal conditions for egg development explain why enlarged clutches often hatched less successfully than control or reduced clutches (Moreno et al. 1991, Siikama"ki 1995, Reid et al. 2000, Engstrand and Bryant 2002). However, these experiments could be artificially inflating the costs of incubating large clutches because birds incubating naturally large clutches may be able to minimize the costs of incubation by adapting, for example, the design or composition of the eggs. Our results suggest that incubating large clutches could represent a cost, at least in terms of hatchability, even when clutch size is mediated by parental decisions. Although we were unable to determine the causes of reduced hatchability in the largest clutches of lesser kestrels, two complementary, non-exclusive physical factors could explain this result. First, large clutches could be covered less efficiently by incubating parents (Bortolotti and Wiebe 1993). In this way, it could be difficult for all eggs of too large clutches to remain in 
(A)

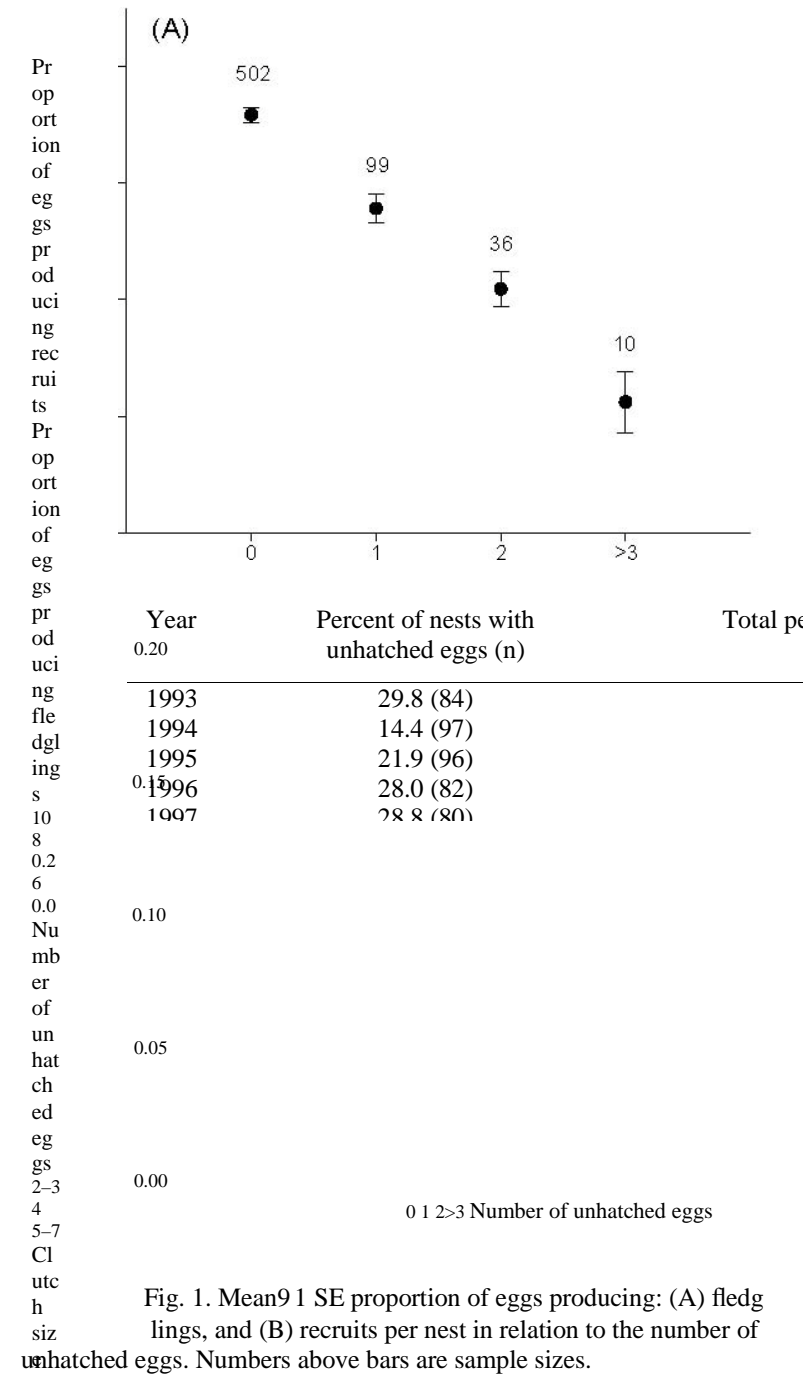

contact with the brood patch of the incubators, those peripheral eggs being more exposed to cooling or heating. This could lead to embryo death, or to reductions in the rate of development, which increases the risk of death via developmental abnormalities (Webb 1987). Second, temperature and humidity of the nest can affect hatching rates, as they are important in determin

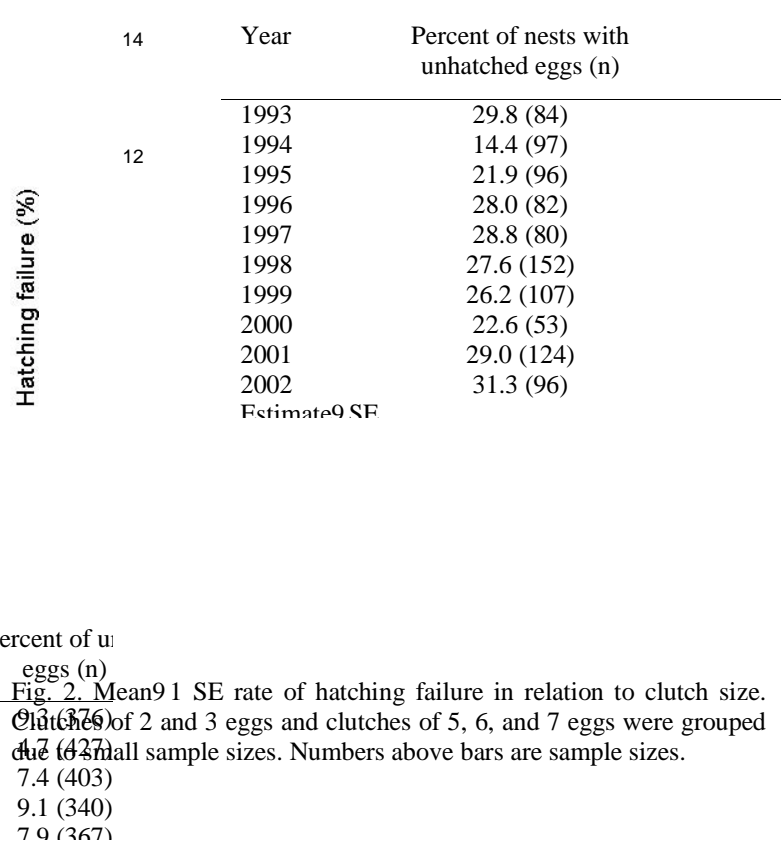

ing rates of water loss of the eggs (Walsberg and Schmidt 1992, Packard and Packard 1993). To the extent that regulation of microclimatic conditions of the nest depends on clutch size, this factor could also explain the higher frequency of non-viable eggs in the largest clutches of lesser kestrels. In fact, Reid et al. (2000) found in other arid area of Spain that starling Sturnus vulgaris eggs incubated in enlarged clutches lost a greater proportion of water than in control clutches, and consequently had higher rates of hatching failure. Other plausible explanations could be related to the time

elapsed between egg-laying and onset of incubation (Veiga 1992), and to potential trade-offs between egg number and quality (Nager et al. 2000). Irrespective of the causal mechanism, our result of reduced hatchability in the largest clutches suggest that parents may suffer costs from incubating large clutches, so the relationship between incubation efficiency and clutch size may be one of the selective forces regulating optimal clutch size in this species. One intriguing question, however, is why three-egg clutches have higher rates of hatching failure than clutches of four eggs. Clutches of three eggs are laid

Table 3. Results of the mixed model explaining causes of hatching failure in lesser kestrels. A binomial error with a logistic link function was used. Colony site was included as a random factor.

\begin{tabular}{|c|c|c|c|}
\hline Year & $\begin{array}{l}\text { Percent of nests with } \\
\text { unhatched eggs (n) }\end{array}$ & $\begin{array}{l}\text { Total percent of unhatched } \\
\text { eggs (n) }\end{array}$ & $\begin{array}{l}\text { Mean proportion of unhatched } \\
\text { eggs per nest (9SE) }\end{array}$ \\
\hline 1993 & $29.8(84)$ & $9.3(376)$ & 0.08690 .140 \\
\hline 1994 & 14.4 (97) & 4.7 (427) & 0.04290 .113 \\
\hline 1995 & $21.9(96)$ & 7.4 (403) & 0.07490 .156 \\
\hline 1996 & $28.0(82)$ & $9.1(340)$ & 0.09490 .173 \\
\hline 1997 & $28.8(80)$ & 7.9 (367) & 0.07990 .145 \\
\hline 1998 & 27.6 (152) & 8.1 (654) & 0.08790 .161 \\
\hline 1999 & $967(1 \cap 7)$ & $\mathrm{q} \cap(\Delta>1)$ & ก ก919 ก 17n \\
\hline
\end{tabular}




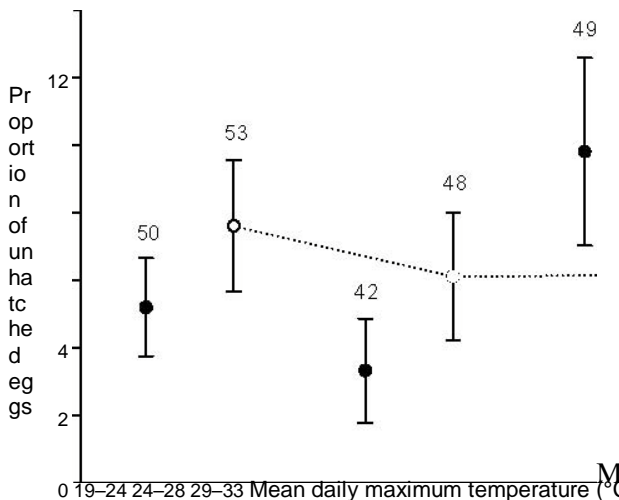

Fig. 3. Mean91 SE proportion of unhatched eggs in relation to mean daily maximum temperature. Data for females with body condition above zero (white circles) and below zero (black circles) are presented. Numbers above bars are sample sizes.

by inexperienced or low-quality individuals (authors' unpubl. data), so nest attentiveness and incubation performance could be the factors underlying the lower rate of hatching success in clutches of this size, in spite that they are theoretically less costly to incubate.

Hatching failure showed a positive relationship with laying date, but this effect disappeared when mean daily maximum temperature during incubation was included into the GLMM model. This indicates that the variable of interest was probably ambient temperature, that generally increases with laying date. Ambient temperature influenced hatching success in clutches laid by females in poor body condition, but not in those laid by females in good condition. Several studies have shown that the female's nutritional state affects her

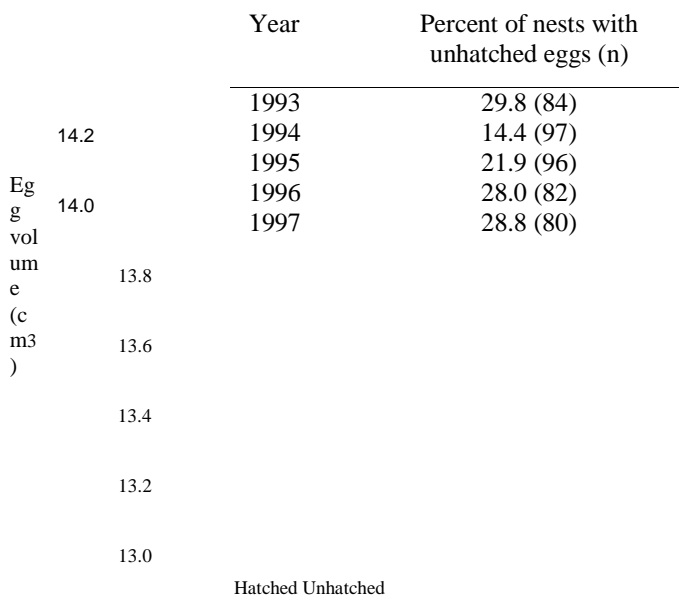

Fig. 4. Mean91 SE egg volume of hatched and unhatched eggs. Numbers above bars are sample sizes. represent a cost or a benefit in terms of hatchability incubation schedule and females in low condition showing lower nest attentiveness (Smith et al. 1989,

nutrient sources during incubation. Parents that spend less time on the nest allow eggs to equilibrate with ambient

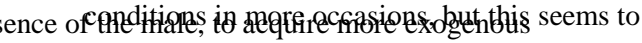
affect hatching success of the kestrels only above a threshold of ambient temperature. The high temperatures reached under the tiles where lesser kestrels breed could be responsible of this

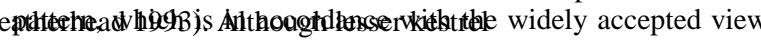
that hyperthermia is more deleterious to the embryo than hypothermia (Webb 1987). Particularly, maintenance of correct nest humidity is important to control rates of water loss from

eggs during incubation (Walsberg and Schmidt 1992), which could require high levels of incubation effort in warm and arid environments such as the study area. In fact, females beginning incubation in poor body condition lose less mass than those in a better condition (authors' unpubl. data), which probably indicates that they are not willing to jeopardize their own condition, but instead pay the costs by failing to regulate nest microclimate successfully and therefore by higher rates of hatching failure. On the other hand, hatching failure was nor repeatable within individuals, indicating that hatchability does not depend on intrinsic properties such as functional fertility or other traits reflecting long-term individual quality.

Hatching failure was negatively related to mean egg volume in the clutch. This could also indicate that poor quality individuals tend to lay small eggs and provide less parental care to the clutch. However, probability of hatching showed a negative relationship with individual egg volume after controlling for clutch "identity", so egg volume per se seems to determine probability of hatching in lesser kestrels. Egg volume may have fitness

Total percent of ur

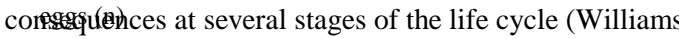
et al. 1993..3(3dgysson et al. 1997), but the majority of studies investigating (4b匹) relationship between egg volume and hatchability. ma fualed to find such an effect (e.g. Smithreg 9367 ) 995 , Clifford and Anderson 2002, but see Wiebe and Bortolotti 1995 for the related American kestrel Falco sparverius). Large eggs have a lower surface-to-volume ratio, which confers thermoregulatory advantages to the embryos because they are less susceptible to temperature fluctuations. Moreover, large eggs may also be of higher nutrient quality, which increases embryonic resilience (Ja“rvinen and Va“isa“nen 1983).

Contrary to Brown and Brown (2001), we found no relationship between colony size and hatching success in lesser kestrels. Thus, coloniality does not seem to 
for this species. We also failed to detect any spatiotemporal relationship between population size and hatchability, and hatching success was not repeatable for individuals breeding together in different years. Kempenaers et al. (1996) found in an outbred population of blue tits that the proportion of unhatched eggs was related to the degree of genetic similarity between the parents as determined by multilocus DNA fingerprinting, and therefore hatching failure was highly repeatable for individuals breeding together in different years. Therefore, our data did not support the hypothesis that genetic similarity between the parents explains levels of hatching failure in lesser kestrels. However, it could be argued that social relationships do not necessarily reflect genetic relationships, and that extra-pair paternity or intraspecific nest parasitism could be confounding our results (Kempenaers et al. 1999). We think that this is unlikely because lesser kestrels show low levels of both extra-pair paternity and clutch parasitism (Negro et al. 1996), although the use of molecular techniques is necessary to advance further in this question.

In conclusion, hatching failure could be an important component of fitness in lesser kestrels that is affected by several factors acting simultaneously. We found a non-linear relationship between clutch size and hatching failure that could play an important role in the evolution of optimal clutch size in this species. Contrary to most studies on wild populations, we also found a positive relationship between egg volume and probability of hatching that could be explained by the higher quality of large eggs in terms of thermoregulatory and nutritional advantages. We also reported a negative relationship between hatching success and ambient temperature, so it seems to be an upper threshold of temperature above which the risk of lethal heating of the embryo increases. Additionally, the effect of temperature on hatching success was only evident for females in poor body condition, suggesting that this effect is behaviourally-mediated. Although all these findings are important to improve our understanding of hatching failure, the precise mechanisms by which these factors affect hatchability are not clear, so more research is needed. Particularly, effort should be devoted to unravel whether the relationship between clutch size and hatching failure is mediated by the incubation capacities of the parents and/or microclimatic features of the nest, and whether nest attentiveness of both male and female is related to their physiological state during incubation.

Acknowledgements -We are very grateful to A. Gajón, R. Lo'pez, J. A Dona'zar, M. G. Forero, O. Ceballos, Y. Menor, F. Hiraldo, I. Luque, J. M. Grande, and R. Jovani for their help with the fieldwork. Financial support was partially provided by collaborative projects with Diputación General de Aragón (1994) -95 and 2000 -02), SEO/BirdLife (1998)-2000)

D.G.I.C.Y.T. PB93 -0040, D.G.E.S. PB96 -0834, and program
LIFE 2000NAT/E/7297 “'Conservacio’n del habitat de nidificación de Falco naumanni en Arago'n”,

\section{References}

Anderson, D., Reeve, J. and Bird, D. 1997. Sexually dimorphic eggs, nestling growth and sibling competition in American kestrels Falco sparverius. -Funct. Ecol. 11: 331 -335.

Aparicio, J. M. 1997. Costs and benefits of surplus offspring in the lesser kestrel (Falco naumanni ). -Behav. Ecol. Sociobiol. 41: 129 -137.

Bensch, S., Hasselquist, D. and von Schantz, T. 1994. Genetic similarity between parents predicts hatching failure: nonincestuous inbreeding in the great reed warbler? -Evolution

48: $317-326$

Bijlsma, S., Hagemeijer, E. J. M., Verkley, G. J. M. and Zollinger, R. 1990. Reproducción del cernı́calo primilla en Extremadura, 1987. -In Gonza'lez, J. L. and Merino, M. (eds). El cernícalo primilla (Falco naumanni ) en la Penı́nsula Ibé́rica. Instituto Nacional para la Conservación de la Naturaleza, Madrid, pp. 91 -99.

Birkhead, T. R., Veiga, J. P. and Fletcher, F. 1995. Sperm competition and unhatched eggs in the house sparrow. -J. Avian Biol. 26: 343 -345.

Bortolotti, G. R. and Wiebe, K. L. 1993. Incubation behaviour and hatching patterns in the American kestrel Falco sparverius. -Ornis Scand. 24: $41-47$

Brown, C. R. and Brown, M. B. 2001. Egg hatchability increases with colony size in cliff swallows. -J. Field Ornithol. 72: 113 -123.

Charlesworth, D. and Charlesworth, B. 1987. Inbreeding depression and its evolutionary consequences. -Ann. Rev. Ecol. Syst. 18: 237 -268.

Cicho'n, M. 2000. Costs of incubation and immunocompetence in the collared flycatcher. -Oecologia 125: 453 -457.

Clifford, L. D. and Anderson, D. J. 2002. Clutch size variation in the Nazca booby: a test of the egg quality hypothesis. -Behav. Ecol. 13: 274 $-279$

Crawley, M. J. 1993. GLIM for ecologists. -Blackwell Scientific Publications, Oxford.

Dona'zar, J. A., Negro, J. J. and Hiraldo, F. 1992. Functional analysis of mate-feeding in the lesser kestrel (Falco naumanni ). -Ornis Scand. 23: 190 -194.

Engstrand, S. M. and Bryant, D. M. 2002. A trade-off between clutch size and incubation efficiency in the barn swallow Hirundo rustica -Funct. Ecol. 16: 782 -791.

Gemmell, N. J. and Allendorf, F. W. 2001. Mitochondrial mutations may decrease population viability. -Trends Ecol. Evol. 16: 115 -117.

Gill, V. A., Hatch, S. A. and Lanctot, R. B. 2002. Sensitivity of breeding parameters to food supply in black-legged kittiwakes Rissa tridactyla . -Ibis 144: 268-283.

Gorman, H. E. and Nager, R. G. 2003. State-dependent incubation behaviour in the zebra finch. -Anim. Behav. 65: $745-754$.

Hendricks, P. and Norment, C. J. 1994. Hatchability of American pipit eggs in the Beartooth Mountains, Wyoming. -Wilson Bull. 106: 392 $-399$.

Hoyt, D. F. 1979. Practical methods of estimating volume and fresh weight of birds eggs. -Auk 96: 73 -77.

Hunt, G. L. and Hunt, M. W. 1973. Clutch size, hatching success, and eggshell-thinning in western gulls. -Condor 75: 483 -486.

Ilmonen, P., Taarna, T. and Hasselquist, D. 2002. Are incubation costs in female pied flycatchers expressed in humoral immune responsiveness or breeding success? -Oecologia 130: 199-204

Ja"rvinen, A. and Va ïsa"nen, R. A. 1983. Egg size and related reproductive traits in a southern passerine Ficedula hypo- 
leuca breeding in an extreme northern environment. -Ornis Scand. 14: $253-262$.

Jones, G. 1987. Time and energy constraints during incubation in free-living swallows (Hirundo rustica ): an experimental study using precision electronic balance. -J. Anim. Ecol. 56: 229 -245.

Kempenaers, B., Adriaensen, F., van Noordwijk, A. J. and Dhondt, A. A. 1996. Genetic similarity, inbreeding and hatching failure in blue tits: are unhatched eggs infertile? -Proc. R. Soc. Lond. B 263: 179 -185.

Kempenaers, B., Congdon, B., Boag, P. and Robertson, R. J. 1999. Extrapair paternity and egg hatchability in tree swallows: evidence for the genetic compatibility hypothesis? -Behav. Ecol. 10: 304 -311.

Koenig, W. D. 1982. Ecological and social factors affecting hatchability of eggs. -Auk 99: 526 -536.

Lessells, C. M. and Boag, P. T. 1987. Unrepeatable repeatabilities: a common mistake. -Auk 104: 116 -121.

Littell, R. C., Milliken, G. A., Stroup, W. W. and Wolfinger, R.

D. 1996. SAS system for mixed models. -SAS Institute, Cary, USA.

Mallory, M. L. and Weatherhead, P. J. 1993. Incubation rhythms and mass loss of common goldeneyes. -Condor 95: 849 -859.

Milonoff, M., Po“ysa“, H. and Runko, P. 2002. Reproductive performance of common goldeneye Bucephala clangula in relation to age and lifespan. -Ibis 144: 585 -592.

Moreno, J. and Carlson, A. 1989. Clutch size and the costs of incubation in the pied flycatcher Ficedula hypoleuca. -Ornis Scand. 20: $123-128$.

Moreno, J. and Sanz, J. J. 1994. The relationship between the energy expenditure during incubation and clutch size in the pied flycatcher Ficedula hypoleuca. -J. Avian Biol. 25: 125 130.

Moreno, J., Gustafsson, L., Carlson, A. and Pa“rt, T. 1991. The cost of incubation in relation to clutch-size in the collared flycatcher Ficedula albicollis, -Ibis 133: 186 -193.

Morrow, E. H., Arnqvist, G. and Pitcher, T. E. 2002. The evolution of infertility: does hatching rate in birds coevolve with female polyandry? -J. Evol. Biol. 15: 702 -709.

Nager, R. G., Monaghan, P. and Houston, D. C. 2000. Withinclutch trade-offs between the number and quality of eggs: experimental manipulations in gulls. -Ecology 81: 13391350.

Negro, J. J., Dona'zar, J. A., Hiraldo, F., Herna'ndez, L. M. and Ferna'ndez, M. A. 1993. Organochlorine and heavy metal contamination in non-viable eggs and its relation to breeding success in a Spanish population of lesser kestrels (Falco naumanni ). -Environ. Poll. 82: 201 -205

Negro, J. J., Hiraldo, F. and Dona'zar, J. A. 1997. Causes of natal dispersal in the lesser kestrel: inbreeding avoidance or resource competition? -J. Anim. Ecol. 66: 640 -648.

Negro, J. J., Villarroel, M., Tella, J. L., Kuhnlein, U., Hiraldo, F., Dona'zar, J. A. and Bird, D. M. 1996. DNA fingerprinting reveals a low incidence of extra-pair fertilizations in the lesser kestrel. -Anim. Behav. 51: $935-943$.

Newton, I. and Rothery, P. 2002. Age-related trends in different aspects of the breeding performance of individual female Eurasian sparrowhawks (Accipiter nisus ). -Auk 119: 735

$$
748 .
$$

Packard, M. J. and Packard, G. C. 1993. Water-loss from eggs of domestic fowl and calcium status of hatchlings. -J. Comp. Physiol. 163: $327-331$.

Potti, J. and Merino, S. 1996. Causes of hatching failure in the pied flycatcher. -Condor 98: 328 -336.

Reid, J. M., Monaghan, P. and Ruxton, G. D. 2000. The consequences of clutch size for incubation conditions and hatching success in starlings. -Funct. Ecol. 14: 560 -565.

Rothstein, S. I. 1973. Variation in the incidence of hatching failure in the cedar waxwing and other species. -Condor 75: 164 -169.

Serrano, D. $\quad$ and Tella, J. L. 2003. Dispersal within a spatially structured population of lesser kestrels: the role of spatial isolation and conspecific attraction. -J. Anim. Ecol. 72: 400 -410.

Serrano, D., Forero, M. G., Dona'zar, J. A. and Tella, J. L. 2004 Dispersal and social attraction affect colony selection and dynamics of lesser kestrels. -Ecology 85: 3438 -3447.

Serrano, D., Tella, J. L., Dona'zar, J. A. and Pomarol, M. 2003. Social and individual features affecting natal dispersal in the colonial lesser kestrel. -Ecology 84: 3044 -3054.

Serrano, D., Tella, J. L., Forero, M. G. and Dona'zar, J. A. 2001. Factors affecting breeding dispersal in the facultatively colonial lesser kestrel: individual experience vs. conspecific cues. -J. Anim. Ecol. 70 568-578.

Siikama ki, P. 1995. Are large clutches costly to incubate -the case of the pied flycatcher. -J. Avian Biol. 26: 76 -80.

Smith, H. G., Ka“llander, H., Hultman, J. and Sanze'n, B. 1989. Female nutritional state affects the rate of male incubation feeding in the pied flycatcher Ficedula hypoleuca. -Behav. Ecol. Sociobiol. 24: 417 -420.

Smith, H. G., Ohlsson, T. and Wattermark, K. -J. 1995. Adaptive significance of egg size in the European starling: experimental tests. -Ecology 76: 1 -7.

Spencer, K. A. and Bryant, D. M. 2001. State-dependent behaviour in breeding barn swallows (Hirundo rustica ): consequences for reproductive effort. -Proc. R. Soc. Lond. B 269: 403 -410.

Tatner, P. and Bryant, D. M. 1993. Interspecific variation in daily energy expenditure during avian incubation. -J. Zool.

231: 215-232

Tella, J. L., Bortolotti, G. R., Forero, M. G. and Dawson, R. D. 2000 The $\mathrm{T}$-cell mediated immune response and return rate of American kestrels are positively correlated with parental clutch size. -Proc. R. Soc. Lond. B 267: 891 -895.

Tella, J. L. 1996. Ecological constraints, costs and benefits of coloniality in the lesser kestrel -PhD thesis, University of Barcelona, Barcelona, Spain.

Tella, J. L., Forero, M. G., Dona'zar, J. A., Negro, J. J. and Hiraldo, F. 1997. Non-adaptive adoptions of nestlings in the colonial lesser kestrel: proximate causes and fitness consequences. -Behav. Ecol. Sociobiol. 265: 253 -260.

Tella, J. L., Forero, M. G., Hiraldo, F. and Dona'zar, J. A. 1998 Conflicts between lesser kestrel conservation and European agricultural policies as identified by habitat use analysis. -Conserv. Biol. 12: 593 $-604$

Thompson, D. L., Monaghan, P and Furness, R. W. 1998. The demands of incubation and avian clutch size. -Biol. Rev.

73: $293-304$

Veiga, J. P. 1992. Hatching asynchrony in the house sparrow: a test of the egg-viability hypothesis. -Am. Nat. 139: 669 675 .

Walsberg, G. E. and Schmidt, C. A. 1992. Effects of variable humidity on embryonic development and hatching success of mourning doves -Auk 109: 309 -314.

Webb, D. R. 1987. Thermal tolerance of avian embryos -a review. -Condor 89: 874 -898.

Wetton, J. H. and Parkin, D. T. 1991. An association between fertility and cuckoldry in the house sparrow, Passer domesticus. -Proc. R. Soc. Lond. B 245: 227 -233.

Wiebe, K. L. and Bortolotti, G. R. 1995. Egg size and clutch size in the reproductive investment of American kestrels. -J. Zool. Lond. 237: 285 $-301$.

Wiebe, K. L. and Martin, K. 2000. The use of incubation behaviour to adjust reproductive costs after egg laying. -Behav. Ecol. Sociobiol. 48: $463-470$.

Williams, T. D., Lank, D. B., Cooke, F. and Rockwell, R. F. 1993. Fitness consequences of egg-size variation in lesser snow geese -Oecologia 96: 331 -338.

Zeh, J. A. and Zeh, D. W. 1996. The evolution of polyandry I: intragenomic conflict and genetic incompatibility. -Proc. R. Soc. Lond B 263: 1711 -1717.

(Received 2 February 2004, revised 29 June 2004, accepted 15 July 2004.) 